Original Article

\title{
ANTI-MICROBIAL EFFECTIVENESS OF LEMON GRASS OIL (CYMBOPOGAN CITRATE) AGAINST AEROBIC AND ANAEROBIC ORGANISMS
}

\author{
AJJAI S. M. ${ }^{1 *}$, P0OJA NAIR' ${ }^{1}$ J. R. LILLY GRACE${ }^{1}$, ROSY VENNILA ${ }^{1}$ \\ 1Department of Microbiology, Saveetha Medical College and Hospital Chennai, Tamil Nadu, India \\ *Email: ajjai2001@gmail.com
}

Received: 12 Sep 2020, Revised and Accepted: 15 Nov 2020

\begin{abstract}
Objective: To find the antibacterial effectiveness of lemon grass (Cymbopogan citrate) oil against aerobic and anaerobic bacteria.

Methods:This is an observational study conducted at Microbiology Clinical laboratory, Department of Microbiology, Saveetha Medical College and Hospital, Chennai. It was done over a period of 3 mo from January to March. The extracts of lemongrass leaves were investigated for its effectiveness
\end{abstract} against Staphylococcus aureus(S.aureus), Escherichia coli(E.coli) and Clostridium perfringens(C.perfringens) by Disc Diffusion assay.

Results:Our study indicates that the extract of lemongrass oil shows antibacterial activity. Among the tested organisms, aerobic organisms were sensitive.

Conclusion: This study thus provides insightful knowledge on antibacterial activity that would lead to further development of lemongrass oil for infectious diseases in the future.

Keywords: Cymbopogan Citrate,Antimicrobial activity, Staphylococcus aureus, Escherichia coli, Clostridiumperfringens

(C) 2021 The Authors. Published by Innovare Academic Sciences Pvt Ltd. This is an open access article under the CC BY license (https://creativecommons.org/licenses/by/4.0/) DOI: https://dx.doi.org/10.22159/ijcpr.2021v13i1.40798. Journal homepage: https://innovareacademics.in/journals/index.php/ijcpr

\section{INTRODUCTION}

The development of bacterial resistance due to misuse and overuse of antibiotics renders the common antimicrobial agents ineffective.This leads to the exploitation of other antimicrobial substances from other sources.Alternatives of developing novel antimicrobial agent from natural sources, such as traditional medicinal plants, spices and herbs need to be explored[1]. Cymbopogan citrate and C. flexuosusis generally known as lemon grass, is an aromatic, evergreen, perennial herb cultivated in tropics and subtropics known for its medicinal purposes all over the world. It is known for its strong lemon taste. It is used widely as an essential ingredient in Asian cuisines. It has high efficacy in combating infection of stomach, prevents peptic ulcer disease, and stimulates digestion and excretion [2]. Lemongrass also holds antidepressant, antioxidant, antiseptic, antispasmodic, bactericidal, fungicidal, nervine and sedative properties. Abundance of citral and essential oil components i. e Geranial, Myrcene, 6-Methylhept-5-en22-one contributes to the anti-microbial activity against a series of micro-organisms[3].

The present study was undertaken to find out the antimicrobial activity of lemongrass oil to treat infections caused by Staphylococcusaureus, Escherichia coli and Clostridium perfringens.

\section{MATERIALS AND METHODS}

This is an observational study conducted at Clinical Microbiology laboratory, Department of Microbiology, Saveetha Medical College Chennai. Test Strains were isolated from the patients over a period of 3 mo from January to March were evaluated and then was used in this study.

\section{Extraction procedure}

Lemongrass leaves were collected, washed using clean water and dried at room temperature for $4 \mathrm{~d}$. The dried plants were kept in a sealed plastic bag and kept in ambient temperature in a dark room. The leaves were then milled to increase the extraction yield. The plant material was soaked in distilled water for $30 \mathrm{~min}$ before the extraction procedure.
$\mathrm{N}$ hexane is used as analytical reagent and solvent extraction method was followed. 150g of the dry sample of lemongrass was placed in a 1 litre clean flat bottom flask. $500 \mathrm{ml}$ of $\mathrm{N}$-hexane solvent were poured into the flask. The flask and content were allowed to stand for $36 \mathrm{~h}$. 200 mlof Ethanol was added to it and the mixture was then transferred to $500 \mathrm{ml}$ separating funnel and separated by a process called liquid/liquid separation process. The content of the separating funnel was allowed to come to equilibrium, which separated into two layers depending on their different density. The lower Ethanol extract and the upper Hexane layer were collected into two separate $250 \mathrm{ml}$ beaker and were placed in a water bath at $78{ }^{\circ} \mathrm{C}$. This was done to remove the ethanol leaving only the natural essential oil[4].

\section{Isolation of Staphylococcusaureus}

The samples collected areinoculated on mannitol salt agar and is incubated overnight. The Staphylococcuscolonies identified by their bright yellow colonies were then subjected to coagulase test, gram staining and catalase test. They were then subjected to various morphological and biochemical tests, including oxidase test, Motility test,indole, ornithine, Methyl Red,VogesProskeur, lipid hydrolysis, starch hydrolysis and gelatinase test [5].

\section{Isolation of Escherichia coli}

The sample suspension is inoculated into MacConkey agar and is incubated for $18-24$ hour at $37^{\circ} \mathrm{C}$. Escherichia coli colonies are identified tentatively by their characteristic pink, round mediumsized colonies. A loop of the isolates was inoculated into nutrient broth for further investigation[6].

\section{Isolation of Clostridium perfringens}

Samples were inoculated in cooked meat medium and incubated anaerobically at $37{ }^{\circ} \mathrm{C}$ for $24 \mathrm{~h}$ in anerobic jar. Samples were streaked on Sulphite polymyxinsulphadiazine SPS agar plates. They were incubated anaerobically and the colonies were gram stained and subcultured on Brain Heart Infusion (BHI)agar plates. This was done until they were free of contaminating bacteria. The pure colonies were streaked on 5\% sheep blood agar and egg yolk agar plates. They were incubated anaerobically for 24 hour. Clostridium perfringens colonies were identified by their characteristic double 
zone of hemolysis around them on blood agar and zone of opalescence around the colonies on egg yolk agar. For further use, they were then preserved at $-80{ }^{\circ} \mathrm{C}$ as glycerol stock $(25 \%$ glycerol in BHI broth [7].

\section{Disc-diffusion assay}

The agar diffusion assay was performed with Muller Hinton agar according to the Kirby-Bauer disc diffusion method as per the CLSI guidelines. The strains of Staphylococcusaureus, Escherichia coli and Clostridium perfringens were seeded in Muller Hinton agar and incubated in $37{ }^{\circ} \mathrm{C}$ shaking incubator overnight. Incubated strains were mixed with warm Muller Hinton agar and poured into petri dish and cooled to room temperature. $1 \%, 5 \%$ and $10 \%$ of $60 \mu \mathrm{l}$ of lemongrass was loaded on sterilised paper $\operatorname{disc}(8 \mathrm{~mm})$. It was placed upside down on the surface of MHA and incited at $37^{\circ} \mathrm{C}$ for $24 \mathrm{~h}$. The diameter of the zone was measured after incubation [8].

\section{RESULTS}

The extract from the leaves of lemon grass shows the inhibitory effect against aerobic organisms likeStaphylococcus aureus and Escherichia colishowing $24 \mathrm{~mm}$ of the zone of inhibitionand no inhibitory effect against anaerobic organism Clostridium perfringens were observed.



Fig.1: Clostridium perfringens(anaerobic organism)

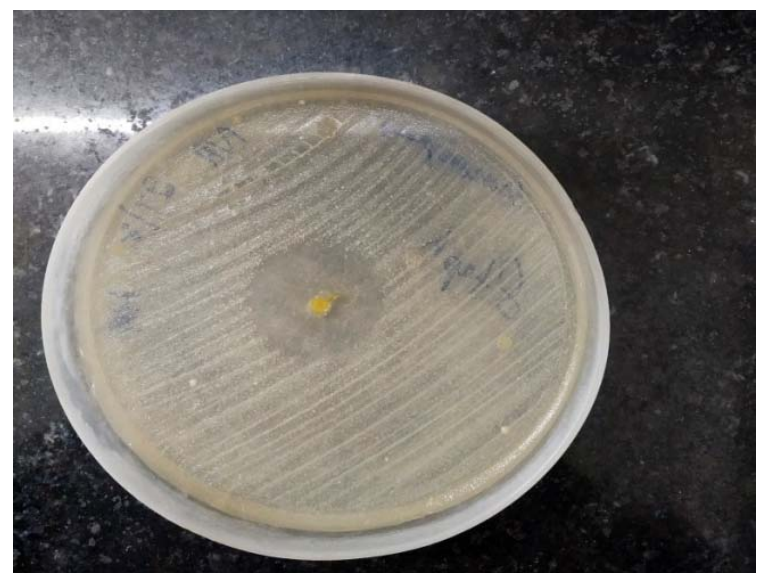

Fig.2: Staphylococcus aureus(aerobic organism)

\section{DISCUSSION}

Development of plant essential oils as natural antimicrobial agents has shown enormous positive potential. The main components of antimicrobial activity of essential oil that are volatile could be developed for agricultural applications. Natural products are usually less toxic when compared to synthetic chemicals. They are also natural products are easily bio-degraded and therefore harmful effects on the environment and public health are lower $[9,10]$. The results obtained indicated that aerobic organisms are more sensitive that anaerobic organisms. Clostridium perfringens were found resistant at all concentrations. For antibacterial treatment against antibiotic-resistant bacterial infections, lemongrass oil in combination with antibiotics could be of potential use. Also, most plant extracts have an inhibition effect on gram-positive organisms than gram-negative organisms. This inhibition effect has been related to active components [11-13].

\section{CONCLUSION}

Lemongrass essential oil has the potential to be used as an antimicrobial treatment against aerobic organisms. This study thus provides an insightful knowledge on antibacterial activity that would lead to further development of lemongrass oil for infectious diseases in future.

\section{FUNDING}

Nil

\section{AUTHORS CONTRIBUTIONS}

All the authors have contributed equally.

\section{CONFLICT OF INTERESTS}

Declared none 


\section{REFERENCES}

1. Shin S, Lim S. Antifungal effects of herbal essential oils alone and in combination with ketoconazole against trichophyton spp. J ApplMicrobiol 2004;97:1289-96.

2. Carbajal D, Casaco A, Arruzazabala L, Gonzalez R, Tolon Z. Pharmacological study of Cymbopogoncitratus leaves. J Ethnopharmacol1989;25:103.

3. Negrelle RRB, Gomes EC. Cymbopogoncitratus (DC) stapf chemical composition and biological activities. RevistaBrasileiraPlantasMedicinais2007;9:80-92.

4. Arputha Bibiana M, Selvamani P, Latha S. In vitro antimicrobial evaluation of extracts, oil and fractionated geranio ofcymbopogancitratusan aromatic grass. Int J EngSci 2012;3:583-90.

5. RahimaBegum, SyedaTasneemTowhid, Mohammad Moniruzzaman, Zakaria Mia,Mohammad Ariful Islam. Study of Staphylococcus aureus from clinical samples in savar, Bangladesh. Res J Microbiol2011;6:884-90.

6. Gebeyehu, SurraandRobi, DerejeandChaluma, Negera. Isolation and identification of escherichia coli, salmonella and pasteurella from holding grounds of live-bird markets at Addis Ababa. Ethiopia Afr J Microbiol Res 2018;12:754-60.

7. Sikander, ParvaizandWani, Shakil, Wani, Aasim, Hussain, et al. Isolation,identification and molecular characterization of clostridium perfringens from poultry in Kashmir valley, India.J EntomolZool Studies2017;5:409-14.

8. Boyanova L, G Gergova, R Nikolov, S Derejian, E Lazarova, N Katsarov, et al. Activity of bulgarianpropolisagainst 94 helicobacter pylori strains in vitro by agar-well diffusion, agar dilution and disc diffusion methods. J Med Biol2005;5:481-3.

9. Kurita N, Makoto M, Kurane R, Takahara Y. Antifungal activity ofcomponents of essential oils. AgricBiolChem 1981;45:945-52.

10. Deepak Ganjewala, Ruchika Mittal, Ashish Kumar Gupta, Martha Premlatha,ReetikaDawar. Antibacterial properties of lemongrass (CymbopogonflexuosusSteud) wats essential oils in single form and combination of honey against drug-resistant pathogenic Bacteria. J Biol Active Prod Nat 2014;4:278-85.

11. BehboudJafari, AmirrezaEbadi, BabakMohammadiAghdam,ZarifehHassanzade. Antibacterial activities of lemon grass methanol extract and essence on pathogenic bacteria. Am-Eur J Agric Environ Sci 2012;12:10426.

12. Jae Young Choi, DerejeDamte, Seung Jin Lee, Jong ChoonKim, SeungChun Park.Antimicrobial activity of lemongrass and oregano essential oil against standard antibiotic-resistant staphylococcus aureus and field isolates from chronic mastitis cow.Int J Phytomed 2012;4:134-9.

13. Onawunmi GO, Yisak W, Ogunlana EO. Antibacterial constituents in the essential oil of cymbopogoncitratus (DC.) Stapf J Ethnopharm 1984;12:279-86. 